\title{
Literatura y enfermería: Fuentes y saberes para investigación em historia
}

\section{Literature and nursing: sources and knowledge for research in history}

\section{Literatura e enfermagem: fontes e saberes para pesquisa em história}

\author{
Taka Oguisso ${ }^{1}$, Onã Silva ${ }^{2}$ \\ ${ }^{1}$ Enfermeira e advogada. Professora Titular. Escola de Enfermagem da Universidade de São Paulo (aposentada). Membro do \\ Grupo de Pesquisa em História e Legislação da Enfermagem \\ ${ }^{2}$ Enfermeira. Doutora em Enfermagem. Graduada em Artes Cênicas. Poetisa do Cuidar. Presidente da Academia \\ Internacional de Poetas e Escritores de Enfermagem. Escreve diversos gêneros literários. Brasília, DF. \\ Cómo citar este artículo en edición digital: Oguisso, T., \& Silva, O. (2017). Literatura e enfermagem: fontes e saberes para \\ pesquisa em história. Cultura de los Cuidados (Edición digital) 21,47. \\ Recuperado de http://dx.doi.org/10.7184/cuid.2017.47.11 \\ Correspondencia:Taka Oguisso. Av. Dr. Enéas de Carvalho Aguiar, 419 - CEP 05403-000 - \\ Cerqueira César - São Paulo - Brasil. \\ Correo electrónico: takaoguisso@usp.br \\ Recibido: 07/07/2016; Aceptado: 20/12/2016
}

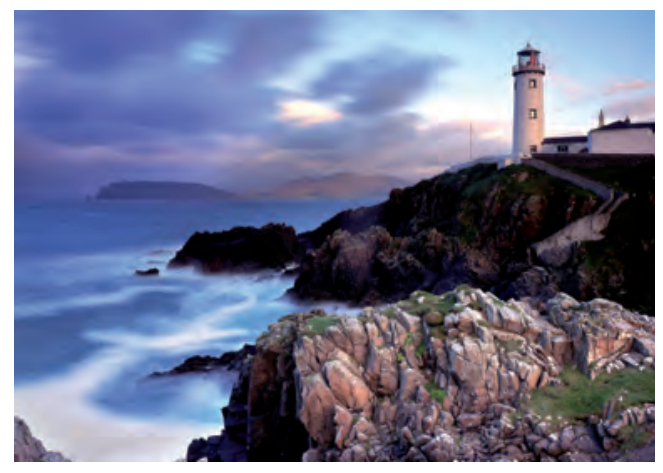

\section{ABSTRACT}

As a profession, nursing needs to define its humanitarian character and the caring culture through literature in support of its professional identity. Objectives: a) to present historical data of publications on nursing within literature of Brazilian and foreign authors; b) to identify contemporary nurses with production and publication in the literature field; c) to reflect on the interfaces between literature and nursing as humanistic knowledge for the caring art. Method: historical study based on documen- tary analysis of literary works. Primary sources were literary works published

by Brazilian or by foreign writers referring to nursing or nurses. Outcomes: After reading the literary texts by selected writers, were drawn out dialogues, texts or information related to nursing or the nurse's job performed by the fictitious characters created by the writers. Conclusion: In fact, literature as an art and effective knowledge field for nursing studies and researches deserves more attention due to the humanistic, philosophical and more inclusive vision and the new look not addressed only to the world of contemporary sophisticated technology of the profession.

Key words: Nursing, nursing history, literature.

\section{RESUMEN}

Como profesión la enfermería necesita definir su caracter humanitario y una cultura de cuidados mediada por la literatura en favor de 
su identidad profesional. Objectivos: a) presentar datos históricos de publicaciones sobre enfermería, en obras de autoria de escritores brasileños y extrangeros; b) identificar enfermeros contemporáneos con producción y publicación en el campo de la literatura; c) reflexionar sobre las interfaces entre la literatura y la enfermeria como saberes humanísticos para el arte de cuidar. Método: Se trata de un estudio histórico basado en análisis documental de obras de literatura. Las fuentes primarias fueron las obras publicadas de escritores brasileños y estranjeros que tengan hecho referencia a la enfermería o la función del enfermero. Resultados: Despues de leídas las obras de escritores selecionados, fueron extraídos diálogos, textos o informaciones referentes a la enfermería o la función de enfermero por los personajes fictícios creados por eses escritores. Conclusiones: De hecho, la literatura como arte y campo del saber para estudios e investigaciones de enfermería.merece más atención por la visión humanística, filosófica y abrangente y con nuevo mirar no dirigido solamente al mundo de la sofisticada tecnologia contemporánea de la profesión.

Palabras clave: Enfermería, historia de la Enfermería, literature.

\section{RESUMO}

Como profissão, a enfermagem precisa definir o seu caráter humanitário e uma cultura cuidativa mediada pela literatura, em prol de sua identidade profissional. Objetivos: a) Apresentar dados históricos de publicações sobre enfermagem, em obras de autoria de escritores brasileiros e estrangeiros; b) Identificar enfermeiros contemporâneos com produção e publicação no campo da literatura; c) Refletir sobre as interfaces entre literatura e enfermagem como saberes humanísticos para a arte do cuidar. Método - Trata-se de um estudo histó- rico baseado na análise documental de obras literárias. As fontes primárias foram obras literárias publicadas, de escritores brasileiros e estrangeiros, que tenham feito referência à enfermagem ou ao ofício de enfermeiro. Resultados: Após leitura das obras de escritores selecionados, foram extraídos diálogos, textos ou informações referentes à enfermagem ou ao ofício de enfermeiro pelos personagens fictícios criados por esses escritores. Conclusões: De fato, a literatura como arte e campo do saber para estudos e pesquisas da enfermagem merece mais atenção, pela visão humanística, filosófica e abrangente e com um novo olhar não dirigido apenas ao mundo da sofisticada tecnologia contemporânea da profissão.

Palavras-chave: Enfermagem, história da Enfermagem, literatura.

\section{INTRODUÇÃO}

Uma profissão dedicada ao bem-estar humano e melhoria social precisa cultivar, apreciar e produzir saberes literários que formem e expressem o seu caráter humanitário. Como profissão, a enfermagem precisa definir o seu caráter humanitário e uma cultura do cuidar mediada pela literatura, em prol de sua identidade profissional - cuja realidade é dominada pela tecnologia, direcionada pela ciência e orientada por crises.

John Stone, médico cardiologista, escritor e poeta, em seu livro "No país de corações", descreveu como a literatura pode ser útil aos profissionais de saúde. Margretta Styles e Patrícia Moccia, qualificadas enfermeiras americanas, adaptaram para o mundo da enfermagem as considerações de Stone. Refletindo sobre esse olhar, da literatura para os profissionais de saúde podem ser destacados os seguintes benefícios: 
- Poderosa ressonância entre os saberes da enfermagem e literários;

- Enfermeiros e escritores extraem das mesmas fontes, isto é, do encontro com as pessoas e suas indeléveis histórias e o uso hábil e competente dos sentidos;

- A literatura tem função laboratorial, pois as pessoas podem inspirar uma série de estórias que, misturadas ao tempo, formam fascinantes contos;

- A literatura oferece oportunidades de catarse, inspirações pessoais e apoio;

- A literatura não é algo extracurricular; é um dado concreto, não um apêndice;

- A literatura proporciona oportunidade para reflexão;

- Escrever um texto literário é terapêutico em si e por si.

O estudo de literatura relacionada à enfermagem constitui um laboratório propício, provocativo e catártico e até eventual apoio para enfermeiros. Pode também favorecer um movimento para que os cursos de enfermagem no seu papel de educar em nível de graduação ou pós-graduação - possam infundir a cultura e a literatura no currículo, por meio de palestras e atividades literárias e de humanidades.

Ler e escrever sobre os fatos cotidianos põe uma face humana no conteúdo biopsicossocial e aprofunda o significado intrínseco da enfermagem. Ademais, envolver-se na literatura torna o profissional mais culto, com visão mais ampla, enriquecendo sua vida e sua prática. Todas as formas literárias são produções importantes: poemas, biografias, ensaios, contos, romances, artigos, editoriais ou estórias abrangendo todos os tempos, culturas e nações.

O que é literatura? Diferentes dicionários a definem ora como a arte de compor ou escrever trabalhos artísticos em prosa ou verso
(Aurélio); ora como arte de compor escritos, em prosa ou em verso, de acordo com princípios teóricos ou práticos (Michaelis); e também como a arte da utilização estética da linguagem escrita, arte literária (Houaiss). Todos os três dicionaristas da língua portuguesa são unânimes em afirmar que a literatura é uma arte.

Sendo uma arte, essa escrita deve caracterizar-se pela excelência - na forma ou expressão - ou ainda pelas ideias de interesse permanente ou universal. Ao contrário de livros-texto ou relatórios técnicos, a literatura deve conduzir o leitor ao discurso ou narrativa e levá-lo a alcançar a profundidade da compreensão ou do sentimento. Exemplificando, a partir de um texto cientifico é possível conhecer os últimos achados sobre a fisiologia do envelhecimento, mas a literatura possibilita saber como é a experiência de envelhecer e quais são as percepções dos idosos. Assim, a literatura oferece uma conexão vital entre o profissional e o leigo porque o fato torna-se compreensível e interessante a ambos. A literatura faz interfaces entre as profissões e campos do saber, pelo grau de desenvolvimento intelectual, sensibilidade e valorização. A literatura é duradoura e não envelhece. Pode refletir a época em que foi escrita, mas a beleza, irrefutabilidade e agudeza de conteúdo são duradouras. A literatura é uma escavação antropológica, nela estão incorporadas camadas de nuances culturais antigas e modernas, e valores a serem descobertos, examinados e lembrados.

Considerando tratar-se de um aspecto ainda pouco estudado e discutido pela maioria dos profissionais de enfermagem, ou seja, as interfaces entre enfermagem e literatura, embora pareça não haver relação entre uma arte abstrata como a literatura e uma arte concreta como enfermagem, foram definidos os seguin- 
tes objetivos: a) apresentar dados históricos de publicações sobre enfermagem, em obras de autoria de escritores brasileiros e estrangeiros; b) identificar enfermeiros contemporâneos com produção e publicação no campo da literatura; c) refletir sobre as interfaces entre a literatura e a enfermagem como saberes humanísticos para a arte do cuidar.

\section{METODOLOGIA}

Trata-se de um estudo histórico utilizandose a técnica da análise documental em obras de literatura sobre a enfermagem e o ofício de enfermeiro.

Quanto às fontes de pesquisa primárias, relativas às obras literárias publicadas, com inserção de referências relativas à enfermagem e/ ou ao ofício de enfermeiro, foram selecionadas para este estudo: a) obras de escritores brasileiros a partir do período do Romantismo até o Modernismo; b) obras de escritores estrangeiros do século XIX e início do século XX.

Nessa coleta de dados, foram identificados seis escritores brasileiros, três escritores portugueses e três escritores britânicos. As obras dos escritores selecionados foram cuidadosamente lidas e analisadas, extraindo-se diálogos, textos ou informações referentes à enfermagem ou ao ofício de enfermeiro realizado pelos personagens fictícios, criados por esses escritores.

Quanto aos enfermeiros contemporâneos que escrevem ou escreveram textos literários, foram selecionados quatro profissionais, autores de produções e publicações literárias expressivas e reconhecidas na história da enfermagem.

Também foram levantadas referências secundárias sobre a importância da literatura na história da enfermagem para subsidiar a reflexão e discussão do artigo.

\section{DESARROLLO DEL TEMA}

Reflexões sobre as interfaces entre a literatura e a ciência do cuidar

O componente do cuidar de enfermagem não é mera combinação do científico e do técnico, mas o equilíbrio entre a mente, o coração e as mãos. Patrícia Donahue (1993) refere sobre a ênfase às áreas de ciência e tecnologia, e o temor de que o espírito cada vez seja menos valorizado com o passar do tempo. Ela reafirma que o espírito foi essencial ao desenvolvimento da arte de enfermagem: "a essência real da enfermagem, como qualquer fina arte, está não nos detalhes mecânicos da execução, nem na destreza do executor, mas na imaginação criativa, no espírito sensível, e na compreensão inteligente que permanece na retaguarda dessas técnicas e habilidades. Sem isso, a enfermagem pode-se tornar um ato comercial cheio de habilidades e não uma profissão, propriamente dita, ou uma fina arte" (Donahue, 1993, p. 7). Ela vaticina que "todos os rituais e cerimônias que nosso moderno culto de eficiência pode projetar e todo o elaborado equipamento científico não irão nos salvar se os aspectos intelectuais e espirituais em nossa arte estiverem subordinados ao fator mecânico da execução" (Donahue, 1993, p. 7).

A enfermagem necessita usar conhecimentos e princípios das ciências humanas no cuidado integral às pessoas, interagindo com elas, respeitando-as ao entrar na sua privacidade ou intimidade para realizar um cuidado específico. Visando compreender melhor a dimensão intrínseca do paciente ou cliente, os profissionais necessitam de saberes das ciências humanas, que não devem ser reduzidos para acomodar mais saberes científicos no agir da enfermagem. Nota-se que vem sendo esquecida a luta realizada pelas pioneiras para incorporar estas ciências no ensino e prática de 
enfermagem e manter vivo o espírito humanitário e social da profissão - sua essência e força vital. Ou seja, esse espírito permite o equilíbrio entre o aspecto científico e técnico do cuidado. Portanto, a competência no cuidado requer conhecimento da filosofia e da história da profissão, formando a postura desejável do ponto de vista legal, cultural, ético-profissional e técnico-científico.

Parafraseando Donahue (1993), é tempo de lembrar que a fase em que estamos devese à visão e à luta de nossas pioneiras, e perguntar-nos se tal visão tem sido, ou vem sendo ampliada, ou ao menos sustentada. Ou se o espírito ou arte de cuidar está vagarosamente desaparecendo da sociedade quando o foco humanitário deveria tornar-se valor supremo. Será que o cientificismo está avançando mais rápido e amplamente no ensino de enfermagem, atropelando e sobrepujando o sentido humanitário, ético, cultural e social da profissão? Haverá algo vital na missão social da enfermagem que está faltando?

Paterson e Zderad (1988) afirmam que, quando a arte e humanidade são incluídas no ensino de enfermagem, deveriam ocorrer efeitos humanitários na ação de cuidar, reconhecidos como influências da civilização moderna. $\mathrm{Na}$ enfermagem, esses efeitos são percebidos como elementos do humanitarismo e da compaixão, em contraposição à tendência da despersonalização que costuma acompanhar a tecnologia científica e a mecanização, que deveriam estimular a criatividade imaginativa que alarga a perspectiva da pessoa sobre tal situação humana em seu mundo. Descrições sobre o sofrimento ou outros aspectos da condição humana, encontrados na poesia, drama ou outro gênero literário, são mais minuciosos e próximos da realidade do que aqueles encontrados em típicos livros técnicos.

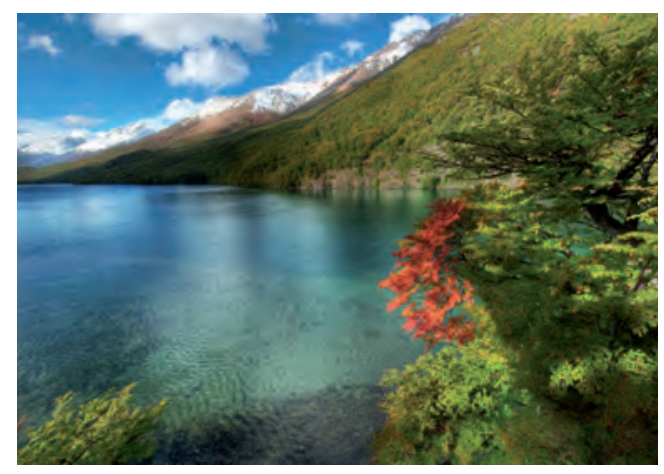

A prática da enfermagem reflete o preparo educacional de seus profissionais que recebem um grande e reforçado peso da ciência e metodologia positivista. Mas as artes e humanidades continuam sendo complementos imprescindíveis. A ciência busca a descoberta de leis gerais e a arte revela a singularidade do indivíduo, o ser único e indivisível dentro da coletividade e do mundo.

Estudos científicos exigem estrita conformação à metodologia e replicabilidade. A arte é muito mais livre e única em seu estilo. Obviamente, a ciência abre a mente dos profissionais para mudanças e inovações, mas o pano de fundo permanece no senso de imutabilidade e constância do ser humano com suas necessidades. A ciência provê o enfermeiro de conhecimento técnico no qual basear suas decisões, mas estão nas artes e humanidades os instrumentos para que o profissional possa analisar os valores jacentes no exercício da prática de enfermagem.

De fato, nos eternos questionamentos sobre o significado da enfermagem, nenhum termo tem sido utilizado e invocado mais consistentemente do que cuidado. Muito já se escreveu sobre os conceitos do cuidado. Ainda que a enfermagem não seja a única profissão a prestar cuidados, pois, em seus respectivos âmbitos, a fisioterapia, a psicologia, a nutrição, o serviço social e a medicina prestam cuidados 
de algum tipo. Apesar das discussões em torno de curar e cuidar, reconhece-se que cuidar é muito mais abrangente. Quando o curar chega ao seu limite, resta ainda muito a cuidar; seja como forma de aliviar o sofrimento, proporcionar conforto, manter a higiene, assegurar uma posição favorável que possibilite ou facilite a realização das necessidades humanas básicas, entre outros cuidados que podem ser prestados pela enfermagem.

Chao (1993) afirma que cuidado é um fenômeno universal e que o cuidar é essencial à existência, ao crescimento, ao desenvolvimento e à sobrevivência humana. Cuidar inclui a interação entre pessoas no tempo, espaço e interações entre quem cuida e quem recebe o cuidado. Localizar a pessoa para cuidar, no lugar certo e na hora exata, diante de quem lhe pode realizar a assistência é a questão maior no processo de cuidar.

O melhor da enfermagem é aquele momento em que se pode compartilhar com os outros os mais importantes e significativos acontecimentos da vida humana - o nascimento e a morte, o bom-dia e o adeus, os começos e os fins. E, ainda, assistir ao triunfo do espírito e do corpo sobre a doença e a morte, mas também experimentar a dor de saber que alguns pacientes irão morrer e quanto alívio poderá ser dado (Black, 1993). Nesta reflexão introdutória, observa-se que o ponto essencial entre enfermagem e literatura está exatamente nessa partilha de experiências e sentimentos vivenciados.

\section{Legado de Florence Nightingale para a histó- ria, a enfermagem e a literatura}

Débora pode ser considerada a primeira enfermeira registrada na história por cuidar de Rebeca, segundo consta no livro de Gênesis 35,8: "Foi então que morreu Débora, ama de Rebeca. E foi ali sepultada, ao pé de Betel, debaixo de um carvalho, ao qual se chamou carvalho dos Prantos" (Bíblia Sagrada Ave Maria, 1987)

O texto bíblico acima mostra que o significado da história pode ser encontrado na literatura. A história permite especulação e reflexão. Ela pode lançar luzes sobre as origens das questões e conflitos, oferecendo bases analíticas que, potencialmente, levam à resolução. A história pode abrir as portas de fontes inusitadas de informações que ajudam no desenvolvimento do pensamento sobre fenômenos específicos. O pensar crítico não pode ser formado sem o reforço do estudo da história. Não basta apenas procurar fatos do passado, mas refletir sobre eles, descobrir relações com outros fatos, levantar inferências, e até mesmo usar a imaginação para cruzar eventos. Fatos isolados não têm valor até que se descubram os seus significados.

Margretta Madden Styles ${ }^{1}$ (1930-2005) afirmava que Florence Nightingale é um símbolo permanente e duradouro da enfermagem, embora alguns a considerem como uma mera ancestral; outros a viram como déspota e tirana, ou excêntrica e maluca. Mas podemos aceitá-la pelo que foi e fez: uma pessoa com as suas fortalezas e fragilidades. Ela foi poderosa em seus dias. Plantou as sementes da moderna enfermagem. Seu nome sobrevive e, acima de tudo, é universalmente associado à enfermagem, enfermeiras e ao público. Mais importante do que o fato de ela ser o nosso mais duradouro símbolo é o reconhecimento do que ela merece ser. Ela representa muitos dos valores que continuamos a prezar. As origens de mui-

\footnotetext{
${ }^{1}$ Foi presidente da Associação Americana de Enfermeiras, de 1986-1988, e, também do Conselho Internacional de Enfermeiras (CIE), de 1993-1997, em Genebra, Suíça.
} 
tos movimentos da enfermagem de hoje podem ser devidas ao legado de Florence.

Styles, que não se considerava historiadora, nem teorista de enfermagem, mas sendo o que foi e acreditando nas impressões deixadas por Florence em sua vida, impregnou seu orgulho de ser enfermeira voar nas asas dos fragmentos de sua legenda. Entre suas impressões sobre Florence Nightingale, e a interface entre enfermagem e literatura, podem ser destacadas:

É assombrosa a extensão do intelecto e interesse de Florence, cuja mente concebeu o que suas mãos fizeram ao prestar cuidados diretos, e também forjaram um ativismo social surpreendente para a época.

Florence era uma mulher original e liberada que assumiu uma nova autoestima, rejeitando convenções sociais e conforto para abrir caminho para uma chamada das então aliadas para a boa educação em enfermagem. Essa foi uma afirmação pessoal dela sobre a importância do nosso trabalho.

Florence trouxe racionalidade, teoria e ciência - algumas vezes brilhantes, outras vezes rudimentares, outras vezes até erradas - para a prática clínica e a administração dos serviços de saúde. Podemos orgulhar-nos por ela ter sido chamada de "estatisticista apaixonada".

Florence fazia uma política astuta e sagaz, movida pela sua militância, sempre inspirada em seus apelos arrebatadores como ao proclamar que "nenhum sistema irá resistir se não marchar para frente".

Já em seu tempo, Florence foi uma ativista do meio ambiente, pregando veementemente sobre a necessidade de saneamento, higiene e vida saudável nas coletividades para poder preservar a vitalidade como pacientes. Isso há mais de um século antes que os cuidados primários de saúde fossem elevados mundial- mente à categoria de um verdadeiro evangelho em Alma Ata (1978) pela Organização Mundial da Saúde.

Outras profissões, como nutrição e dietética e as várias terapias, saúde pública e a administração de serviços de saúde, lembram-se dos ensinamentos de Florence e incluem-se também como seus legatários. Mas "Florence é nossa”, proclama Styles.

As impressões de Styles mostram uma Nightingale feminista, política, cientista, ambientalista, visionária e reformadora - sem dúvida um perfil admirável e surpreendente. Há outros aspectos humanitários e sensíveis de Florence, como, por exemplo, uma carta de próprio punho, de 1855, à família de um soldado morto na Guerra da Crimeia, de febre tifoide; na missiva ela descreve os últimos momentos do soldado. Supõe-se que ela escreveu essa carta à noite, lutando contra a desesperança e a fadiga do trabalho diurno, após a ronda noturna, utilizando aquela lâmpada que a celebrizou e tornou-a o símbolo da Enfermagem. Provavelmente, ela escreveu outras cartas para familiares de outros soldados feridos, que ela havia cuidado e tenha se sentido tão profundamente responsável. Podemos orgulhar-nos crendo que muitos enfermeiros, ainda hoje, repetem esse gesto humanitário de mil maneiras e circunstâncias, para continuar essa tradição criada por Florence Nightingale.

"Florence é nossa" e "continua nossa", como proclamava Styles. Sem dúvida, o nome Nightingale é nosso, o ideal persiste, a lâmpada continua acesa e brilhante e o símbolo perdura.

\section{Enfermagem e personagens enfermeiros nas obras de literatura brasileira}

A literatura é duradoura e não envelhece; reflete a época em que foi escrita, mas a beleza, 
a irrefutabilidade e a agudeza de conteúdo permanecem. A literatura é uma escavação antropológica: nela estão incorporadas camadas de nuances culturais antigas e modernas e valores a serem descobertos, examinados e lembrados.

$\mathrm{Na}$ história da literatura brasileira, alguns autores, identificados no presente estudo, citaram a enfermagem ou descreveram personagens no ofício de enfermeiro ou enfermeira em suas obras clássicas.

\section{a) Período literário do Romantismo}

Dentre os autores desse período, podem ser citados José de Alencar (1829-1877) considerado o precursor do romantismo no Brasil, nascido no Ceará. Antes do campo literário, atuou como advogado, jornalista, deputado e ministro da justiça. Aos 26 anos publicou a primeira obra: Cinco Minutos.

Lucíola, quinta obra romântica de José de Alencar, de 1862, é narrada em primeira pessoa, na qual o próprio José de Alencar personifica o personagem Paulo, descrevendo o romance entre ele e Lucíola. Ambos se apaixonam e passam a conviver juntos. E cita-se, um trecho em que ele faz referência à enfermeira:

"Achei instalada em sua casa, como en-

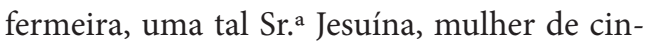
quenta anos, seca e já encarquilhada, com quem embirrei solenemente desde o momento em que a vi. [...] a Sr. ${ }^{a}$ Jesuína tinha sempre um remédio a dar, um travesseiro a endireitar, uma recomendação a fazer."

Na obra, O gaúcho (1870), José de Alencar intitula um capítulo de "O enfermeiro". O personagem Manuel Canho é um menino gaúcho que admira seu pai, um grande conhecedor de cavalos que morre assassinado. Ele nunca o esquece, odeia seu padrasto e, quando este morre, parte para vingar a morte do pai. Segue uma narrativa:
"Manuel passou a noite, como o dia, fazendo o ofício de enfermeiro. Apenas deixava o aposento do doente para ir ver seus amigos, a baia e os outros animais a quem havia acomodado no potreiro (...)."

\section{b) Período literário do Realismo - Naturalis- mo}

Dentre os autores desse período, citamse: Machado de Assis, Lima Barreto e Aluísio Azevedo e as suas respectivas obras e personagens.

Machado de Assis (1839-1908), o maior nome da literatura brasileira, escritor, poeta, dramaturgo, contista entre outros qualificativos, destacou-se no período do Realismo. Ele também foi fundador e o primeiro presidente da Academia Brasileira de Letras, instituída em 1897, permanecendo nesse cargo até sua morte.

Citam-se, a seguir, três obras de sua autoria que têm referências à enfermagem e o conto "O Enfermeiro".

Memórias póstumas de Brás Cubas, obra de Machado de Assis, publicada em 1881, enfatiza o personagem Brás Cubas, homem rico e solteiro que, depois de morto, se dedica a narrar a sua própria vida. Existem cenas referentes à enfermagem, tais como:

"Eu estava só, em casa, com um simples enfermeiro; podíamos falar um ao outro, sem perigo (...) Não importa a idade do adulado; a mulher há de ter sempre para ele uns ares de mãe ou de irmã, ou ainda de enfermeira, outro ofício feminil (...)."

Na obra Quincas Borba (1891), o autor Machado de Assis conta a história de Pedro Rubião de Alvarenga, ex-professor primário, que se torna enfermeiro e discípulo do filósofo Quincas Borba, que falece no Rio, na casa de Brás Cubas. Rubião é nomeado herdeiro 
universal do filósofo, sob a condição de cuidar de seu cachorro, de nome Quincas Borba também.

"Durou o cargo de enfermeiro mais de cinco meses, perto de seis. Era real o desvelo de Rubião, paciente, risonho, múltiplo, ouvindo as ordens do médico, dando os remédios às horas marcadas, saindo a passeio com o doente, sem esquecer nada (...)."

Machado de Assis, no livro Dom Casmurro (1915), cria o personagem Bentinho: órfão de pai, cuidado com desvelo pela mãe (Dona Glória), protegido do mundo pelo círculo doméstico e familiar (tia Justina, tio Cosme, José Dias), destinado à vida sacerdotal, devido à antiga promessa de sua mãe. A vida do seminário, no entanto, não o atrai e tem um romance com Capitu, filha dos vizinhos. $\mathrm{Na}$ história há referências à enfermagem: "Como minha mãe adoecesse de uma febre, que a pôs às portas da morte, quis que Capitu lhe servisse de enfermeira. Prima Justina, posto que isto a aliviasse de cuidados penosos, não perdoou à minha amiga a intervenção.”.

No livro Várias histórias (1896), Machado de Assis publicou o conto intitulado "O enfermeiro". Nesse conto, o autor narra em primeira pessoa a história do enfermeiro Procópio José Gomes Valongo, último a cuidar do Coronel Felisberto, um homem rabugento, exigente, excêntrico, temperamental e insuportável, que sofria de aneurisma, reumatismo e outras três ou quatro afecções menores. Procópio fora convidado pelo vigário de uma vila interiorana, para cuidar desse Coronel, por considerá-lo uma pessoa inteligente, entendida (trabalhava num colégio em Niterói, onde copiava estudos de teologia de um padre), discreta e paciente que poderia servir de enfermeiro, mediante um bom ordenado. $\mathrm{O}$ vigário recomendoulhe ainda mansidão e caridade para cuidar do
Coronel, que gastava mais com enfermeiros do que com remédios. Com o tempo, passou a ser maltratado pelo Coronel, que o insultava, humilhava e o injuriava, batendo-lhe com a bengala, ou atirando-lhe um prato de mingau ou a moringa de água. Certo dia, a moringa arremessada com violência atingiu a face esquerda do enfermeiro, que furioso lançou-se sobre o paciente e acabou por esganá-lo. Percebendo que o paciente estava morto, foi para outro quarto e esperou amanhecer, amargando o momento de raiva que o levara àquele ato extremo, achando ter cometido um crime e que receberia punição certa. $\mathrm{O}$ temor complicou o remorso e era difícil restituir a paz à sua consciência, maldizia ter aceitado aquele trabalho e os que o haviam convencido a ficar, mesmo depois que ele havia decidido deixar o Coronel. Mas ninguém suspeitou de nada e os funerais foram realizados normalmente. Procópio estava em paz com os homens, mas não estava com a consciência. Regressou ao Rio de Janeiro e logo recebeu um comunicado de que ele, Procópio, era o herdeiro universal conforme testamento deixado pelo Coronel, que, apesar de áspero e duro, soubera ser grato. Achou que a recusa da herança poderia levantar suspeitas e desconfianças. Assim, rumou de novo para a vila para receber a herança do Coronel.

Outro escritor do período do Realismo é Lima Barreto (1881-1922). Filho de pais pobres, ficou órfão de mãe aos seis anos. Abandonou os estudos para trabalhar e sustentar a família. Para aumentar a renda, escrevia textos para jornais cariocas. Escreveu romances, sátiras, contos, textos jornalísticos e críticas.

Lima Barreto criou a obra Triste fim de Policarpo Quaresma (1915), a qual, resumidamente, consta: a primeira parte acontece no

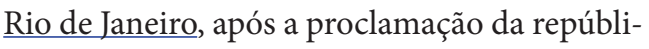
ca brasileira. Na segunda parte, são analisados 


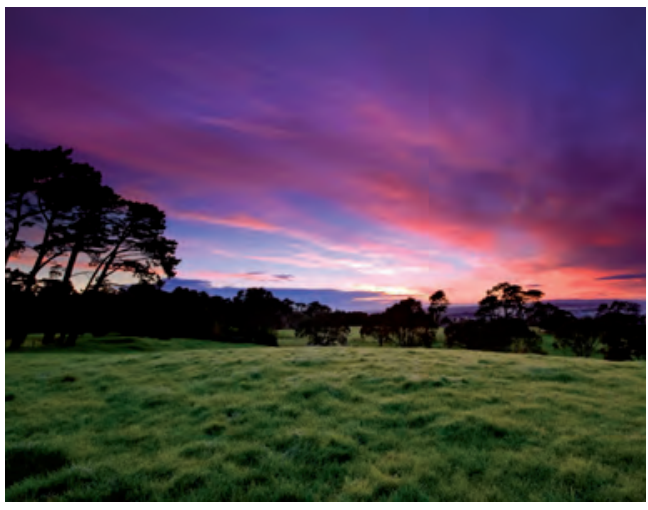

os problemas enfrentados pela porção rural do país. A última parte narra as andanças de Policarpo pela Capital Federal durante a revolta da Armada e mostra sua desilusão final.

"Médico e rico, pela fortuna da mulher, ele não andava satisfeito. (...) Já era médico do Hospital Sírio, onde ia três vezes por semana e, em meia hora, via trinta e mais doentes. Chegava, o enfermeiro dava-lhe informações, o doutor ia, de cama em cama, perguntando: "Como vai?" "Vou melhor, seu doutor", respondia o sírio com voz gutural."

Considerado o pioneiro do Naturalismo no Brasil, Aluísio Azevedo (1857-1913) nasceu em São Luís, Maranhão. Foi o fundador da Cadeira no 4 da Academia Brasileira de Letras. Autor de diversos livros, entre eles: Uma lágrima de mulher, $\mathrm{O}$ Mulato, Casa de Pensão, O Cortiço, Girândola de Amores, Filomena Borges, O Coruja, O Homem, O Esqueleto, A Mortalha de Alzira e outros.

Casa de Pensão (1884) foi baseado em história real de grande repercussão na época, a Questão Capistrano - crime que envolveu dois estudantes semelhante à narrativa de Aluísio Azevedo. Amâncio é um jovem que veio do Maranhão para o Rio de Janeiro para estudar medicina, hospedando-se na casa de um conhecido da família. O seu modo de vida boêmio gera desentendimentos, então ele se muda para uma pensão. Lá, ele se envolve com Amélia, irmã de João Coqueiro, o dono da pensão.

"Resolveu-se que seria o copeiro quem acompanharia o enfermo durante o resto da noite. $\mathrm{O}$ médico recomendara que dessem o remédio de três em três horas. Lúcia lamentou que, justamente nessa ocasião, a sua Cora estivesse em Cascadura ajudando a uma amiga a morrer, porque ao contrário Amâncio não teria outra enfermeira. "Ah! não havia como aquela mulata para tratar de um doente!..." (...) Ele, às vezes, já se fazia mais doente e mais carecido de cuidados, só para desfrutar os mimos da enfermeira."

\section{c) Período literário do Pré-Modernismo}

Guilherme de Almeida (1890-1969) era advogado (formado pela USP, em 1912), jornalista, poeta, ensaísta e tradutor. Foi membro da Academia Brasileira de Letras, eleito em 1930. Chamado o Príncipe dos Poetas Brasileiros. Em homenagem às enfermeiras, dedicou-lhes o lindo poema intitulado "A mão que nunca falta", atendendo ao pedido de Edith de Magalhães Fraenkel - primeira diretora da Escola de Enfermagem da USP - em maio de 1947, ano da realização do Primeiro Congresso Brasileiro de Enfermagem.

Na poesia "A mão que nunca falta", Guilherme de Almeida identifica a mão da enfermeira que, na falta da mãe que abençoa e da mão do amor-amor que acaricia, restava "sempre a mão paciente e boa de alguém que colhe a lágrima dolente, que estanca o sangue da ferida, que enxuga o suor da fronte ardente e que toma a pulsação da vida, a mão útil de uma íntima estrangeira, a mão piedosa e sábia da enfermeira”.

O poeta soube, com maestria, exprimir o papel do enfermeiro no cuidar do doente, muitas vezes como mãe substituta ou mãe 
profissional. Ainda que a linguagem pareça sentimentalista, melíflua e afetada para os dias atuais - dominados pela objetividade da tecnologia sofisticada e linguagem técnica dos modernos computadores - o poeta exprimiu seu carinho e respeito pelos profissionais da enfermagem no estilo da época.

\section{d) Período literário do Modernismo}

Carlos Drummond de Andrade (19021987) nasceu em Minas Gerais. Foi poeta, cronista, tradutor e contista, formou-se em ciências farmacêuticas (1925), em Ouro Preto, embora não tenha exercido. Ingressou no serviço público em 1934, no Rio de Janeiro; foi chefe de gabinete de Gustavo Capanema, ministro da Educação até 1945. Trabalhou no Serviço de Patrimônio Histórico e Artístico Nacional e aposentou-se em 1962. Desde 1954, colaborava como cronista no jornal Correio da Manhã, e a partir de 1969 no Jornal do Brasil.

No dia 13 de maio de 1954, publicou no Correio da Manhã a crônica intitulada "Ela trabalha em silêncio", referindo-se à enfermeira, analisando com incrível exatidão a histórica luta das profissionais por um lugar ao sol e a falta de reconhecimento social. Essa mesma crônica, com ligeiras alterações formais, foi publicada trinta anos depois no jornal dominical Shopping News - City News, em São Paulo - no dia 20 de maio de 1984, data do encerramento da Semana da Enfermagem ${ }^{2}-$ enfatizando que as enfermeiras continuavam a trabalhar em silêncio, esquecidas em suas justas reivindicações. Lembrou a baixa remuneração e a falta de carreira para enfermeiras. Dado o que ela havia gastado "em esforço e estudo para a boa formação profissional e a responsabilidade das funções tal remuneração era ridícula, em país de eterna inflação".

Drummond afirmou ainda que a enfermagem "não é uma profissão qualquer, mas uma que exige mais do que o comum para seu bom desempenho". Indica "a doçura, modéstia, limpeza de alma, desistência de oportunidades brilhantes em outras formas de realização, interesse profundo pelo próximo, sobretudo pelo que há de doloroso e mesmo repugnante no próximo", como virtudes esperadas de enfermeiras; mas que seria justo dispensar-lhes também atenção especial, garantindo-lhes saúde e bem-estar para que elas pudessem cuidar cada vez melhor do bem-estar e da saúde dos outros.

Nessa época, a Presidente da Associação Brasileira de Enfermagem, Seção São Paulo (1980-1984), Taka Oguisso, agradeceu o autor pela homenagem prestada, mencionando o paradoxo existente de falta de profissionais nos serviços de saúde e desemprego de enfermeiros. A crônica e o ofício da ABEn-SP foram posteriormente reproduzidos na Revista Paulista de Enfermagem, e aquele semanário registrou o recebimento do ofício na edição seguinte, de 27 de maio de 1984.

\section{Enfermagem e personagens enfermeiros nas obras de literatura estrangeira}

$\mathrm{Na}$ história da literatura estrangeira, na presente pesquisa, foram identificados alguns autores que, nas suas obras clássicas, fizeram citações sobre enfermagem ou incluíram personagens no ofício de enfermeiro ou enfermeira.

Entre escritores portugueses são citados: Camilo Castelo Branco, Júlio Dinis, Eça de

\footnotetext{
${ }^{2}$ Semana da Enfermagem - instituída pelo Decreto no 48. 202, de 12 de maio de 1960, para celebrar anualmente, de 12 a 20 de maio, datas nas quais ocorreram, respectivamente, em 1820 e 1880, o nascimento de Florence Nightingale e o falecimento de Anna Nery.
} 
Queiróz e as suas respectivas obras e personagens.

Camilo Castelo Branco (1825-1890) nasceu em Lisboa-Portugal. Foi registrado como filho de mãe incógnita, pelo que se diz, porque seu pai e sua avó não queriam que o nome Castelo Branco estivesse envolvido com alguém de humilde condição. Era escritor multifacetado, cujas obras o posicionaram como uma das figuras mais eminentes da literatura portuguesa.

No romance Amor de perdição (1862), esse autor mostra a saga entre duas famílias que se odiavam, e sucede a paixão de Simão Botelho e Teresa de Albuquerque. Na trama vários sentimentos: ódio, paixão proibida, paixão platônica, desespero, fugas e outros acontecimentos entre os personagens das famílias inimigas. No livro constam diálogos que se referem ao ofício de enfermeira:

"Estamos então bem aliviados! Eu tenho cá a minha vida, e queria que ela fosse a enfermeira do meu doente... És, ou não és, rapariga? disse ele à filha quando ela abriu os olhos, com semblante de envergonhada da sua fraqueza.

A moça ficou encostada ao batente da alcova de Simão.

- Não foi nada boa esta praga que lhe caiu em casa, Mariana! — disse o acadêmico - Fazerem-na enfermeira dum doente, e privaremna talvez de ir costurar na sua varanda, e conversar com as pessoas que passam...”

Júlio Dinis (1839-1871), cujo nome real era Joaquim Guilherme Gomes Coelho, nasceu em Porto-Portugal. Formado pela escola de medicina e cirurgia do Porto (1861), preferiu dedicar-se à literatura e ao ensino universitário. O conjunto de sua obra caracterizou-se pelo estilo direto e espontâneo, sugestivo, voltado para a naturalidade, abordando costumes e relações sociais nas aldeias portuguesas. Dentre as suas obras, a mais bem-sucedida foi
As pupilas do senhor reitor (1867). Seus poemas e dramas tiveram edição póstuma, após sua prematura morte com 32 anos.

Quanto à história do livro As pupilas do Senhor Reitor (1867), ela acontece numa aldeia portuguesa povoada de pessoas bondosas e pelo moralismo de comadres fofoqueiras. Desenrola-se a trama do inocente namoro entre Daniel e Guida, mas o reitor descobre o inocente namoro entre os jovens. O pai, José das Dornas, decide, então, enviá-lo ao Porto para estudar medicina. Dez anos depois Daniel volta para a aldeia, como médico homeopata. Margarida, agora professora de crianças, conserva ainda seu amor pelo rapaz. O romance mostra vários acontecimentos a partir do retorno de Daniel.

"Assim continuou este viver por muitos anos mais, até que a mãe de Clara adoeceu. Durante a moléstia, foi Margarida desvelada e incansável enfermeira, colhendo sempre, em paga dos seus carinhos, modos rudes é ásperos, expressões inequívocas de aversão que nunca deixava de sentir por ela."

"Por isso, entre Daniel, como médico, e Clara, como enfermeira, crescera, rapidamente, certa familiaridade, a qual não pouco concorrer para fazer demorado o exame do doente, cuja moléstia era de uma evidência e de uma fatalidade de êxito, que deviam facilitar a tarefa do seu estudo."

Eça de Queirós (1845-1900) nasceu na cidade portuguesa de Póvoa de Varzim. Aos 16 anos de idade foi estudar Direito em Coimbra. Foi discípulo do escritor francês Gustave Flaubert, de quem recebeu grande influência literária, sendo um dos pioneiros da literatura realista portuguesa. Como romancista, abordou nas suas obras os temas cotidianos, comportamento de pessoas, pessimismo, ironia e humor. Suas obras foram traduzidas em várias 
línguas. É considerado até hoje como um dos principais representantes do realismo português.

O romance realista $O$ crime do Padre Amaro (1875) desenrola-se na província de Leiria, e inicia com apresentação do cenário - Leiria e a sua vida devota - e das personagens principais - Amaro e Amélia. Amaro fica órfão muito cedo, sendo protegido por uma marquesa rica, que lhe torna herdeiro de um legado, mas só na condição de se tornar padre. Termina, a muito custo, o seminário e torna-se pároco em Leiria. É aí que Amaro conhece Amélia e se apaixonam. Esta fica grávida, situação que acarretaria graves consequências para a vida sacerdotal de Amaro. Num ato impensado, este mata o próprio filho, já que Amélia morre após o parto.

"Para Amélia aquele tempo foi um alívio; ao menos ninguém pensava, ninguém reparava nela (...). Demais, os serviços de enfermeira ocupavam-na: como era a mais forte e a mais nova, agora que a S. Joaneira estava estafada de vigílias, era ela que passava as longas noites à beira de D. Josefa..."

"Daí a dois dias o abade Ferrão apareceu restabelecido do seu ataque de reumatismo. Contou a Amélia a bondade do Morgado, que chegara a mandar-lhe todas as tardes, num aparelho de lata com água quente, uma galinha cozida em arroz. Mas era sobretudo a João Eduardo que devia a caridade melhor; todas as suas horas vagas as passava ao pé da cama, lendo-lhe alto, ajudando-o a voltar, ficando com ele até à uma hora da noite num zelo de enfermeiro. Que rapaz! Que rapaz!”

O primo Basílio (1878) é uma sátira moralizadora sobre a burguesia de Lisboa. Conta a história do casal - Luísa e Jorge - que vive pacatamente. Jorge viaja para o Alentejo por motivos profissionais; na ausência do marido,
Luísa é surpreendida pela visita de Basílio, seu primo e amigo de infância, com quem trocara cartas românticas. Seduzida por este, Luísa cai em adultério. Então, a criada de Luísa, de nome Juliana, rancorosa e mesquinha, após descobrir o segredo, faz chantagem, obrigando a patroa a servi-la e exigindo uma grande quantia pelo seu silêncio. A trama continua com vários desdobramentos. Quanto aos diálogos que se refere ao ofício de enfermagem, extrai-se:

“- Tu trata a velha, paparica-a, que ela o que quer é uma enfermeira que a sofra. É rica, não é nada apegada ao dinheiro; é capaz de te deixar uma independência!

Durante um ano Juliana, roída de ambição, foi a enfermeira da velha. Que zelos! Que mimos!

Virgínia era muito rabugenta; a ideia de morrer enfurecia-a; quanto mais ela ralhava com a sua voz gutural, mais Juliana se fazia serviçal. A velha, por fim, estava enternecida, gabava-a às pessoas que a vinham ver, chamava-lhe a sua providência. Tinha-a recomendado muito a Jorge."

Referente aos escritores britânicos, destaca-se a escritora e poetisa Emily Bronte, Archibald Joseph Cronin e Charles Dickens.

Emily Bronte (1818-1848) nasceu em Thornton, Yorkshire, a quinta filha de Patrick Brontë, vigário da Igreja da Inglaterra e Maria Branwell. A empregada Thabitha costumava contar-lhes histórias, e Emily a homenageou como a fiel personagem de Nelly Dean, em "O Morro dos Ventos Uivantes”. Emily e os irmãos criaram, em suas brincadeiras, terras imaginárias (Angria, Gondal, Gaaldine). Tais terras imaginárias eram relatadas em detalhes, jornais e outros artigos que as crianças costumavam escrever, e onde seus soldados de chumbo, presente do pai, costumavam "morar". 
A narrativa de Wuthering Heights (1847) - traduzido para o português como O morro dos ventos uivantes - é realizada em primeira pessoa pelo narrador observador; ressaltando o efeito romântico-gótico, misterioso e melodramático. Entre reviravoltas, a história mostra as diferentes faces dos personagens: todos possuem seu lado bom e mal, retrata a essência humana com defeitos amplificados. É um clássico da literatura inglesa que desperta sentimentos extremos, o ódio ou a adoração, prende o leitor de modo diferente: não para sentir afeto ou simpatia pelos personagens, mas para adorar a história.

"Mal Catherine saía do quarto de Mr. Linton, vinha sentar-se à minha cabeceira. Repartia o seu tempo entre nós dois e não perdia um só minuto com distrações: negligenciou as refeições. os estudos $e$ as brincadeiras. Era a enfermeira mais zelosa que eu já vi; devia ter um coração deveras generoso para ainda lhe sobrar tanto carinho para me dar depois de todo o amor que dedicava ao pai."

Archibald Joseph Cronin (1896-1981) era conhecido como AJ Cronin, famoso escritor do século XX, cujos livros foram traduzidos para inúmeros idiomas e adaptados para o cinema e televisão. Viveu inicialmente em Glasgow e no País de Gales, depois em Londres, mudando-se com a família para a Califórnia, Estados Unidos, no final da década de 1930. Retornou à Europa, residindo em Montreux, na Suíça, onde faleceu. Era filho de pai católico e mãe protestante, nascido na Escócia e formado em medicina, o que lhe deu conhecimento e experiência para escrever sobre doenças dos mineiros de carvão e outros temas. Convocado, serviu como médico no final da Primeira Guerra Mundial, antes de sua graduação em medicina, concluiu o curso em 1919 e recebeu o grau de doutor em medicina em 1925, com

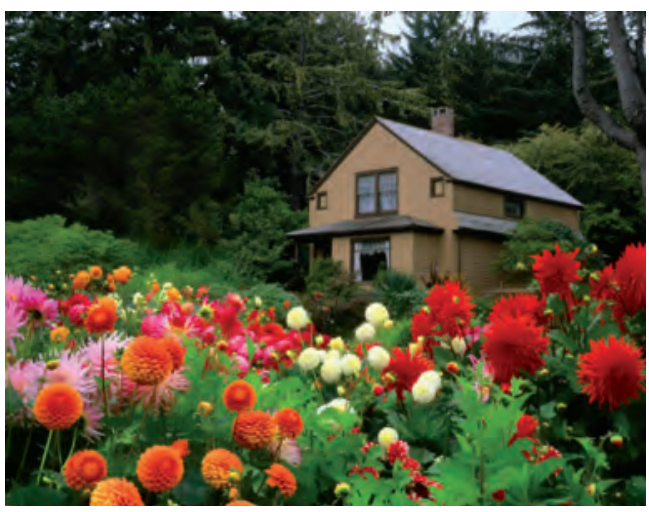

sua tese sobre "história do aneurisma". Praticou medicina por mais de dez anos antes de se dedicar à literatura, mas sua experiência foi valiosa para escrever seus romances, situando com propriedade e realismo suas histórias, inclusive o livro Noites de vigília (1939), no qual descreveu a vida, o trabalho e as responsabilidades de uma enfermeira.

Charles Dickens (1812-1870) foi um dos mais populares escritores da era vitoriana, contribuindo com seus livros para a introdução da crítica social na literatura de ficção inglesa. Entre os mais famosos clássicos encontram-se Oliver Twist, David Copperfield, Christmas Carol e Vida e Aventuras de Martin Chuzzlewit, este último escrito entre $1843 \mathrm{e}$ 1844, após uma viagem aos Estados Unidos. Esses romances atravessaram séculos e continuam ainda hoje a serem editados. Alguns críticos consideram que seus romances não eram muito realistas, pelos parâmetros atuais, mas ele contribuiu para a introdução dessa crítica social. Importante lembrar que esse escritor foi contemporâneo de Florence Nightingale.

\section{Escritores de literatura, profissionais de en-} fermagem, do período contemporâneo

Na história da enfermagem já figuram enfermeiros que estão produzindo escritos literários - romances, ensaios, poemas - sobre as 
suas próprias vidas e sobre assuntos relacionados ao cuidar.

Dentre os profissionais de enfermagem contemporâneos, podem ser citados como precursores na literatura os seguintes nomes: Wanda de Aguiar Horta, Maria Jacyra de Campos Nogueira, Daisy Maria Gonçalves Leite, Onã Silva, José Siles González e outros profissionais que, mais recentemente, estão escrevendo, influenciados por esses precursores.

a) Wanda de Aguiar Horta (1926-1981) nasceu em Belém-Pará. Graduada em enfermagem pela Universidade de São Paulo (USP) e licenciada em História Natural, pós-graduada em Pedagogia e Didática aplicada à Enfermagem. Conquistou doutorado e livre Docência na Escola de Enfermagem Anna Nery, Universidade Federal do Rio de Janeiro (UFRJ). Em 1974, tornou-se professora adjunta da USP e em seguida professora titular. É autora da Teoria das Necessidades Humanas Básicas (NHBs) que subsidia o processo de enfermagem, enfatizando o assistir ao indivíduo em suas necessidades básicas, tornando-o independente, por meio do ensino do autocuidado. Resultado de empenho pessoal, Wanda Horta foi idealizadora, criadora, editora e redatora da revista "Enfermagem em Novas Dimensões" (REND). A estrutura desse periódico incluía: editoriais, artigos originais, traduções, bibliografias, resenhas de pesquisas e lançamento de livros, glossário português/inglês e a seção denominada Arte que publicava poemas, poesias e pinturas relacionadas com o cuidado humano e com a própria enfermagem. Publicou vários poemas na REND.

b) Maria Jacyra de Campos Nogueira (1934-2016) - enfermeira formada pela Escola de Enfermagem da USP (1960), concluiu o mestrado e o doutorado em 1967 e 1973, respectivamente. Sua tese de livre-docência "Fitoterapia popular e enfermagem comunitária" (1983), recebeu apreciação da Fundação de Amparo à Pesquisa do Estado de São Paulo (FAPESP), do Ministério da Saúde, do Ministério do Trabalho e Previdência Social (na época havia muitos ambulatórios e hospitais subordinados a esse Ministério por meio do Instituto Nacional de Assistência Médica da Previdência Social - INAMPS), e da Secretaria de Saúde do Paraná, pois serviram de subsídio para a utilização de plantas medicinais em forma de infuso ou decoto pelos pacientes. Prestou concursos para professor-adjunto e titular, orientou dezenas de dissertações e teses de doutorado. Assessorou durante 5 anos (1979-1984) a Universidade Federal da Paraíba, Centro de Ciências da Saúde, para instalação e funcionamento do Departamento de Enfermagem. Além dos trabalhos técnicos e profissionais, Maria Jacyra escrevia poemas, crônicas e contos. Sua primeira incursão no campo literário foi em 1956, quando escreveu a crônica Um só par de sapatos, publicada no Diário de Notícias, em Ribeirão Preto. Também publicou o livro de poesias Simples estar no mundo, pela Editora Sangirardi (1983). Na RND publicou cinco poesias; na Revista Paulista de Enfermagem seis; e esparsamente em outros diferentes periódicos e em livro de poesias organizado por outros autores.

c) Daisy Maria Gonçalves Leite, nascida e residente em Natal, Rio Grande do Norte é escritora, poetisa e compositora. Graduou-se em enfermagem pela Escola de Enfermagem de Santos, São Paulo, em março de 1963. Ainda aluna, iniciou estudos sobre comunicação do bebê por meio do choro, tendo, em 1964, viajado para a Suécia em busca de no- 
vos conhecimentos sobre o choro infantil, uma vez que, no início da década de 1960, a análise espectrográfica do choro já fazia parte da clínica pediátrica do Departamento de Pediatria do Hospital Karolinska, dirigido pelo Professor John Lind, com quem manteve contato até seu falecimento, em janeiro de 1983. Concluiu mestrado na Escola de Enfermagem da USP, com a dissertação "O Choro do Lactente - Conhecimentos das Enfermeiras no Rio Grande do Norte “ (1979), sob orientação de Maria Jacyra de Campos Nogueira. Tornou-se pioneira no estudo da "comunicação através do choro infantil" no país, merecendo crônica de Dinah Silveira de Queiroz, no Jornal do Povo/RS, na época, embaixatriz do Brasil, em Portugal. Foi também destaque no programa "Fantástico, o Show da Vida", da TV Globo (1981 e 1998), e nas revistas "Veja” (1981), e "Isto é” (1981). Em 1965, já havia sido entrevistada pela Rádio Suécia - no programa em português para Brasil, Portugal e Colônias - como enfermeira brasileira, pesquisadora do choro infantil. Foi fundadora e vice-presidente da Sociedade Brasileira de Enfermeiros Escritores e também presidente e fundadora da Academia Feminina de Letras do Rio Grande do Norte. Formou-se em ciências jurídicas e sociais pela Universidade Potiguar (RN), em 1997. É colunista do Jornal ECOS da Literatura Lusófona. É autora de três livros de poesias: $O$ Livro de Daisy (1979), com prefácio do escritor Luís da Câmara Cascudo; A Primavera Voltou (1999), com prefácio do acadêmico norte-rio-grandense, Jurandir Navarro; e Fragmentos de Mim (2002), prefaciado pelo acadêmico norte-rio-grandense e diretor do Instituto Histórico e Geográfico do Rio Grande do Norte, Enélio Lima Petrovich; além de outros: $O$ choro do Lactente (1979) e O choro do Bebê (2003). Foi referência do "Projeto Zero a Seis", da Funda- ção Roberto Marinho - Rede Globo; “ $A$ vida do Bebê", do Prof. Rinaldo De Lamare, $38^{\circ}$ edição, Editora Bloch; Programa Ensino Pré-escolar-TVU/UFRN (1982). Participou de Coletâneas e revistas culturais nacionais e no exterior, como: Poesias Brasileiras (2001), pela Casa do Livro Editora; Antologia da AJEB Letras (Associação de Jornalistas e Escritoras do Brasil) Fortaleza /CE/2003. Antologia virtual Livro do Passado (2004); Antologia virtual Dia Internacional da Mulher (2005); Antologia virtual Dia Mundial da Poesia (2005) e outras, todas do Portal Português “Cá Estamos Nós”. Recebeu inúmeras homenagens e medalhas, inclusive a medalha de mérito Carlos Drummond de Andrade, no $1^{\circ}$ Encontro Nacional de Academias de Letras, em Caxambu, MG, 2002. Neta pelo lado materno de músico, poeta e compositor, lançou o CD “ Canta pra mim”, boleros de sua autoria, interpretados pelo cantor paraense Émerson Vaughan. Produziu os livros: Boleros de Daisy Etiel, (anagrama de Leite), em 2002, com músicas (boleros) cifradas para violão, e Song Book (2002), composições de Daisy Etiel, com letras cifradas e partituras.

d) Onã Silva - A Poetisa do Cuidar - nasceu em Posse-Goiás, mas reside em BrasíliaDF, Brasil. Despontou nas artes literárias no final da década de 1980, como uma autêntica e qualificada enfermeira, formada também em Artes Cênicas, pós-graduada em Saúde Pública, Mestre em Educação, Doutora em Enfermagem. Atua na Secretaria de Saúde do Distrito Federal como enfermeira. A criatividade e a arte de cuidar em saúde são suas inspirações para a literatura e pesquisas que vem desenvolvendo. Adotou o nome literário de "A Poetisa do Cuidar". É palestrante de temáticas relacionadas com criatividade, ludicidade, teatro e outras. Sua produção de 
quase três décadas no campo literário inclui diversos gêneros: poesia, romance, crônica, dramaturgia, novela, contos e outros. É autora e coautora de livros publicados (individuais e coletivos), bem como de artigos e produções científicas. Tem os seguintes livros publicados: Mas a alegria vem pela manhã (poesia); O Sol da Justiça (poesia); A Quadradinha de Gude (livro infanto-juvenil); Miriã, uma enfermeira bambambã (romance); Histórias da Enfermagem no Universo de Cordel (poesia de cordel); A Derrota de Penina (romance); Anjinho Minho...Mãezinha Minha... (livro infantil); Mundo-Bola (livro infantil); Voa Balão... Voa Imaginação... (livro infantil); Ludicidade e suas interfaces (artigos temáticos); Solange Caetano: tem coragem no nome e enfermagem no sobrenome (poesia de cordel); Poesia nas lentes do monóculo: meus pais (poesia); Cordel do Trabalhador: do labor até o burnô (poesia de cordel), Grandes Enfermeiras: Florence Nightingale e Anna Nery (quadrinhos); Enfermagem com Poesia: a arte sensivel do cuidar (poesias), e outros. Como escritora, sua literatura faz interface peculiar entre as linguagens artísticas e a saúde; pela inovação recebeu, inclusive do RankRecords Brasil (2013), título homologado como primeira escritora a escrever histórias da enfermagem em cordel. Idealizou projetos inéditos como o livro Enfermagem com Poesia: $a$ arte sensivel do cuidar (reunindo poesias, exclusivamente, profissionais da enfermagem, publicado em duas edições); e a Academia IPÊ (Academia Internacional de Poetas e Escritores de Enfermagem) - primeira instituição na área de literatura, dentro da enfermagem, com objetivo literário, composto por 17 acadêmicos empossados, representantes da enfermagem do Brasil, Portugal e Espanha, da qual é atual presidente. Também é acadêmica literária, nas instituições: Academia Infantil de Letras e Artes (AILA); Academia de Letras e Artes do Nordeste Goiano (ALANEG); Academia Internacional de Cultura (AIC); Academia Taguatinguense de Letras (ATL) e Academia Portuguesa de Ex-Libris (Ex-Libris). Tem realizado trabalho pioneiro, voltado para arte e literatura e saúde, com experiências de ações culturais em unidades de saúde (Hospitais, Postos de Saúde, Centros de Atenção) e outros cenários de promoção e cuidados à saúde. Está biografada em livros, dicionários e no Catálogo Literário. Seu trabalho tem sido reconhecido, sendo premiada em vários concursos literários e científicos.

Jose Siles González, enfermeiro, pedagogo, doutor em história e professor catedrático, radicado em Alicante, junto ao Mediterrâneo, na Espanha, além da vasta produção técnica em enfermagem e antropologia, criou um campo comum para estudos e pesquisas conjugados nessas duas áreas que se consubstanciou no periódico regular denominado Cultura de los Cuidados - Revista de Enfermería y Humanidades, fundado em 1997. É o editor e diretor desse periódico desde sua fundação. Publicou diversos livros didáticos dentro de sua área de conhecimento, especialmente, sobre Historia da Enfermagem e sobre Cultura dos cuidados. Entre suas obras literárias incluem-se oito narrativas, sendo a mais antiga publicada em 1986 e a mais recente 2015. En-tre essas obras podem ser destacadas algumas como: A última noite de Erik BiKarbonato, de (Siles, 1991); A delirante travessia do soldado bêbado (e outros contos), (Siles, 1995), A chi-cotada, (Siles, 1997); A vênus de Donegal (Si-les, 2012) y La utopia rastejante (Siles, 2015). Publicou poesias em revistas e livros, de 1996 
a 2014, entre as quais podem ser citadas: Tedio Protocol (Siles, 1996), O sentido do navegante, (Siles, 2000), e O sal do tempo (Siles, 2006). Nove monografias e ensaios foram publicados tais como "Estrutura familiar e função social da mulher em Alicante (1868-1936)" em 1995; "Passado, presente e futuro da enfermagem na Espanha (perspectiva histórica e epistemológica)", em 1999; Antropologia narrativa dos cuidados, em 2000 e Antropologia educativa dos cuidados, em 2009. Recebeu inúmeros prêmios entre os quais podem ser citados: Literários: Café Iruña de novela (Bilbao, 1991), Ciudad de Villajoyosa (1992); cientistas: Castilla La Mancha de pesquisa em Enfermagem, em 1989; o Internacional de História da Enfermagem, concedido pela Universidade Complutense, Madrid, em 1990 e em 1994, Premio Vicente Mojica, de Alicante, em 1992; de Pesquisa em Enfermagem, de Valencia, em 1993, Nacional de Pesquisa em Enfermagem, de 1995; e de Humanismo e Saúde, Alicante, em 2011. Também há publicados artigos sobre a relação entre a poesia e os cuidados (Siles, 2015; Siles y Solano, 2016) ea narrativa e de enfermagem (Siles y Solano, 2014).

\section{CONSIDERAÇÕES FINAIS}

A história da literatura brasileira registra um exemplo de que a arte é contributo ao cuidar. Por meio do conto O Enfermeiro, Machado de Assis, ajudou a divulgar a figura do enfermeiro no século XIX. Considerando-se a época dos fatos, situada pelo próprio escritor em 1860 - e 1896 o ano da publicação - não existia no Brasil enfermeiros na concepção formativa atual, apenas pessoas que cuidavam empiricamente dos doentes, chamados de enfermeiros. Interessante, entretanto, são os qualificativos indicados para ser um bom enfermeiro: inteligência, entendimento, discrição e paciência, além de mansidão e caridade. São adjetivos que eram também indicados por muitos outros autores que escreveram manuais e textos para enfermeiros.

Anos adiante na história, em 1954, novamente um escritor renomado tomou iniciativa inédita, em defesa de enfermeiras, diante do que ele sentia como injustiça social, relativa ao trabalho desempenhado por elas. Relaciona o elenco de qualidades esperadas dos profissionais, ressaltando a singularidade da função cujo exercício exigia "mais do que o comum,", mas a sociedade lhes negava uma justa remuneração.

No Brasil, são mais de 500 mil enfermeiros em exercício (COFEN, 2016), afora os técni$\cos$ e auxiliares de enfermagem. Estamos na linha de frente em todos os rincões do país: regiões inóspitas, tribos indígenas, populações ribeirinhas dos grandes rios ou igarapés, até os centros avançados e sofisticados de serviços e sistemas de saúde. Já temos enfermeiros pesquisadores nas universidades, educadores, gerentes, especialistas (em praticamente todos os ramos do saber), no campo político, em funções executivas em secretarias de saúde, superintendências e empresários de sucesso. Mas observa-se, na história, que ainda são raros os enfermeiros nas áreas de poesia, música, dramaturgia, contos, arte visual e cinema. Este estudo apresentou um pequeno número de enfermeiros atuando na literatura, que já escreveram e publicaram poemas e livros de natureza literária. Registra-se que os enfermeiros identificados na literatura têm uma formação em outros campos do saber - história, pedagogia, artes cênicas -, o que certamente contribuiu para a produção literária.

Por se tratar de campo pouco explorado, é possível que outros benefícios possam ser identificados, mas o importante é abrir espaço 


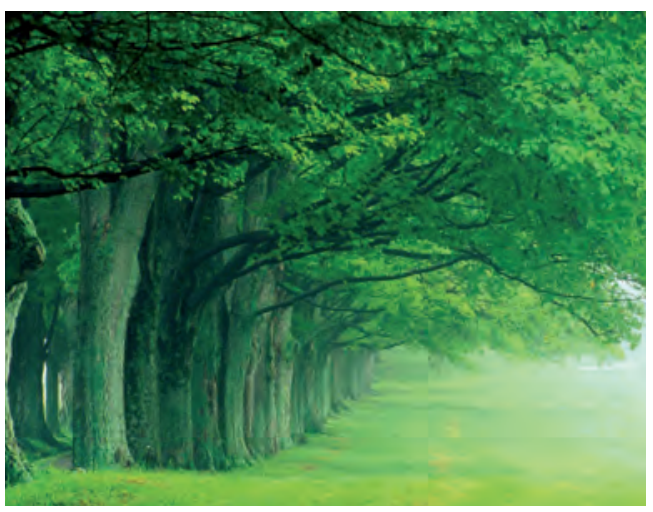

para diálogo com outros profissionais, em busca de interfaces de mútuos interesses e benefícios, possibilitando ampliar os horizontes das pesquisas e enriquecer o campo do saber da enfermagem.

A literatura é arte e campo do saber que enfermeiros pouco têm aproveitado para seus estudos e pesquisas, e que merece maior atenção, pela visão humanística, filosófica e abrangente ao novo olhar da enfermagem para o seu mundo feito de concretudes.

\section{Agradecimento especial}

Os autores agradecem ao professor Maurício Apolinário pela valiosa contribuição neste estudo histórico, identificando alguns escritores de literatura brasileira e estrangeira e as respectivas obras que fazem referência ao ofício da enfermagem.

\section{REFERÊNCIAS}

- Academia IPÊ (Org.) (2016). Enfermagem com Poesia: a arte sensível do cuidar. Curitiba-PR: Editora CRV.

- Alencar, J. O. (1998). Gaúcho. Rio de Janeiro: Ediouro.

- Alencar, J. (1989). Lucíola. São Paulo: Editora Ática.

- Assis M. (1989). Dom Casmurro. Rio de Janeiro: Ediouro, s/d.

- Assis, M. (1991). Memórias póstumas de Brás Cubas. Rio de Janeiro: Ediouro.
- Assis, M. (1995). Quincas Borba. Rio de Janeiro: Ediouro.

- Azevedo, A. (1989). Casa de pensão. São Paulo: Editora Ática.

- Almeida, G. de (1982). A mão que nunca falta. In A.C. Carvalho (Ed.), Escola de Enfermagem da Universidade de São Paulo (p.11). Resumo histórico.

- Andrade, C.D. (1984). Ela trabalha em silêncio. São Paulo: City News.

- Ave Maria (1987). Bíblia Sagrada Ave Maria. São Paulo: Editora Ave Maria.

- Callahan, D. (1990). The priority of care over cure. In What kind of life: limits of medical progress. New York: Simon \& Schuster.

- Chao, Y.M. (1993). A unique concept of nursing care. In M.M. Styles \& P. Moccia (Eds.), On Nursing, a literary celebration: an anthology (pp. 127-129). New York: National League for Nursing.

- Barreto, L. (1989). Triste fim de Policarpo Quaresma. São Paulo: Editora Ática.

- Black, B.P. (1993). Caring in hellish places. In M.M. Styles \& P. Moccia (Eds.), On Nursing, a literary celebration: an anthology (pp131-143). New York: National League for Nursing.

- Branco, C.C. (1983). Amor de perdição. São Paulo: Ática.

- Conselho Federal de Enfermagem (COFEN). (2016). Pesquisa Perfil da Enfermagem no Brasil. Enfermagem em foco, 7(Esp), 6-85.

- Dinis, J. (1987).As pupilas do Senhor Reitor. $8^{\text {a }}$ ed., São Paulo: Editora Ática.

- Donahue, P. (1993). The spirit of nursing. In M.M. Styles \& P: Moccia (Eds.), On Nursing, a literary celebration: an anthology (pp.7-9). New York: National League for Nursing.

- Paterson, J.G., Zderad, L.T. (1988). Humanistic nursing. New York: National League for Nursing.

- Queirós, E. (1989). O Crime do Padre Amaro. São Paulo: Editora Ática.

- Queirós, E. (1988). O primo Basílio. São Paulo: Editora Ática.

- Siles, J. (1991). La última noche de Erik Bikarbonato. Alicante: Aguaclara.

- Siles, J. (1995). Protocolo del hastío. Madrid: Vitruvio. 
- Siles, J. (1997). El Latigazo. Madrid: Huerga \& Fierro.

- Siles, J. (2000). El sentido del navegante. Valencia: Instituto de Estudios Modernistas.

- Siles, J. (2006). La sal del tiempo. Madrid: JHuerga \& Fierrro.

- Siles, J. (2012). La Venus de Donegal. Madrid: Ediciones Libertarias/Prodhufi.

- Siles, J. (2014). Los tripulantes del Líricus. Madrid: Ediciones Devenir.

- Siles-González, J. and Solano-Ruiz, C. (2014). Qualitative Research and Narrative Sources in the Context of Critical and Renal Cares. Open Journal of Nursing, 4, 385-401. Recuperado de http://dx.doi.org/10.4236/ ojn.2014.46045

- Siles, J. (2015). La Utopía Reptante. Madrid: Verbum.

- Siles, J. (2015). Walt Whitman, Poesía y Cuidados. Cultura de los Cuidados,19(43), 12-16. Recuperado de http:// dx.doi.org/10.14198/cuid.2015.43.02

- Siles, J. y Solano, C. (2016). Sublimity and beauty A view from nursing aesthetics. Nurs Ethics, 23(2),154-166. doi:10.1177/0969733014558966
- Silva, O. (1984). Mas a alegria vem pela manhã. Goiânia - Goiás: Gráfica Betel.

- Silva, O. (2012). Histórias da enfermagem no universo de cordel. Brasília: Thesaurus.

- Silva, O. (2013). Histórias da enfermagem no universo de cordel. brasília-DF: Thesaurus Editora.

- Silva, O. (2016). Grandes Enfermeiras: Florence Nightingale e Anna Nery. Brasília-DF: Cuidarte.

- Silva, O., Alves, E.D. (Org.) (2015). Enfermagem com Poesia: a arte sensível do cuidar. $1^{\text {a }}$. ed. Brasília-DF: Thesaurus Editora de Brasília.

- Stone, J. (1990). In the country of hearts. Journeys in the art of medicine. New York: Delacorte Press.

- Styles, M.M., Moccia, P. (1993). On Nursing, a literary celebration: an anthology. New York: National League for Nursing.

- Taylor, M.C. (2009). Para reinventar a universidade. O Estado de São Paulo, São Paulo, edição de 03-05-2009, Caderno A, p. 27. Original publicado em The New York Times.

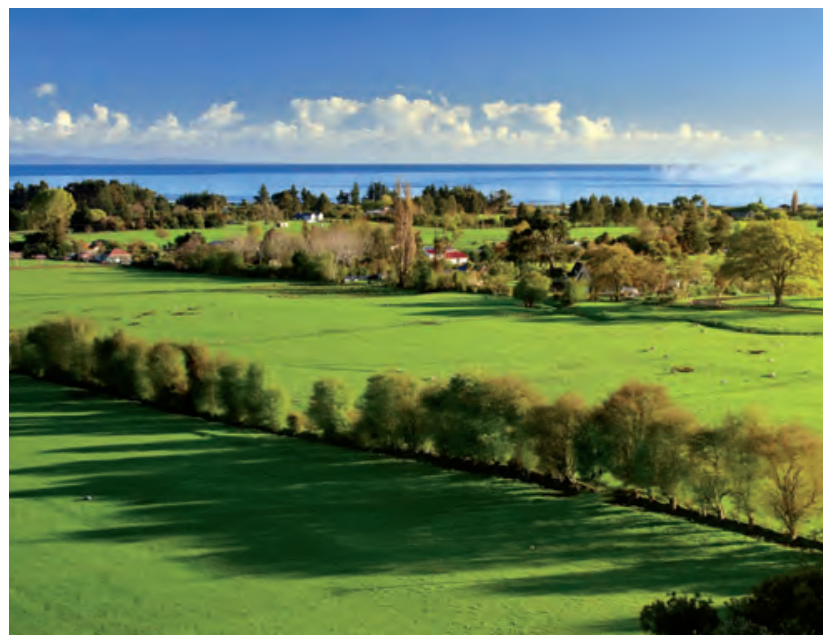

